\title{
The Effect of Surgery Type on the Quality of Life in Breast Cancer Patients: A Mini Review
}

\author{
Elham Bahrami ${ }^{1}$, Kefayat Chaman Ara ${ }^{2 *}$ and Mohammad Amin Bahrami ${ }^{3}$ \\ ${ }^{1}$ Department of Obstetrician and Gynecologist, Ayatollah Khatami Hospital, Iran
}

${ }^{2}$ Department of Obstetrician and Gynecologist, Kowsar Hospital, Iran

${ }^{3}$ Department of Healthcare management, Shahid Sadoughi University of Medical Sciences, Iran

*Corresponding author: Kefayat Chaman Ara, Department of Obstetrician and Gynecologist, Kowsar hospital, Shiraz, Iran

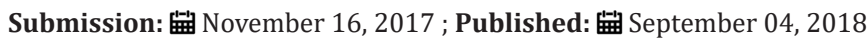

\begin{abstract}
Breast cancer is the most common women cancer around the world. The disease, its diagnosis and treatment impose considerable negative physical and psychosocial effects on the patients and severely threaten their quality of life. Surgical treatment with different types is the most used option for breast cancer treatment. In this mini-review we briefly reviewed the effects of different surgery types on the breast cancer patients' quality of life. Current evidence shows that breast preserving surgery saves patients' quality of life more than other surgery types.
\end{abstract}

\section{The Statement of Problem}

Breast cancer is a common cancer that has one of the highest rates of morbidity and mortality among all types of cancers. This rate is still increasing around the world, especially in developing countries. Studies show that only between 2008 and 2012 the incidence of breast cancer has increased by $20 \%$. During the same period, the mortality rate of breast cancer has increased by $14 \%$ [1]. Breast cancer is the most common cancer in women and in some countries accounts for more than $20 \%$ of all malignancies [2]. This cancer is the second leading cause of death in women after cardiovascular diseases. Current evidence shows that more than 200 million women in the world are suffering from breast cancer [3]. Therefore, in many countries, breast cancer is considered a public health issue. Despite the fact that most cancers have major negative consequences, the text focuses specifically on breast cancer. This is due to the epidemiological importance and the high prevalence of breast cancer as well as its widespread psychosocial outcomes [4]. Diagnosis and treatment of breast cancer also include a stressful situation not only from a physical point of view but also from a psychological point of view, because patients with breast cancer must, in addition to overcoming the disease and its treatment and bearing the potential threatening of life, bear its psychosocial effects. [1,4] Breast cancer treatment includes two types of surgical and non-surgical treatment. Surgical treatment is the most common type of breast cancer treatment and includes breast preservative surgery and mastectomy [5]. The surgical treatment of breast cancer imposes extensive psychological effects on the patients. Some of these consequences are the loss of physical image, decreased self-esteem, mood disorders, distress, depression, fear, social isolation and self-regulatory, self-perception and psychosocial adjustment problems [6-14]. Therefore, breast cancer surgery can be a potential threat to patients' quality of life [5]. Many studies have examined the quality of life of women with breast cancer and documented the impacts of surgical treatment on that. In this mini-review we briefly reviewed some of these studies. The purpose of this brief review is to highlight the importance of life quality of women undergoing breast cancer surgery with the aim of policy applications.

\section{Study 1}

Zana et al. [15] investigated the effect of conserving surgery on the life quality of breast cancer patients. 74 patients with breast cancer who had a follow-up period of at least 12 months after disease diagnosis were contributed in this study. These patients consisted of 2 groups those who were treated with conserving surgery and those with modified radical mastectomy. All patients filled out a questionnaire which consisted from 51 questions related to different aspects of quality of life. The results of this study showed that conserving surgery has more positive effects on the quality of life than the modified radical mastectomy.

\section{Study 2}

Marko et al. [16] studied the impact of breast cancer surgery on some aspects of quality of life such as self-esteem and sexual life. In this study, 207 patients with breast cancer who received surgical treatment were included. These patients included 3 groups: breast 
conserving surgery $(n=83)$, modified radical mastectomy without breast reconstruction $(\mathrm{n}=105)$ and mastectomy with delayed breast reconstruction $(n=16)$. All patients evaluated and reported the effects of their treatment through a self-report questionnaire. The results of the study showed that patients who had undergone under breast conserving surgery had the most satisfaction with their treatment which followed by mastectomy with delayed breast reconstruction and finally by modified radical mastectomy without breast reconstruction, although all patients reported the negative effects of surgical treatment of their condition.

\section{Study 3}

Akca et al. [14] in their study examined the effects of various types of surgery on the quality of life of breast cancer patients. 250 patients in three groups including breast preserving surgery $(n=27)$, modified radical mastectomy $(n=194)$ and simple mastectomy $(n=29)$ contributed in this study. All patients completed a quality of life questionnaire. The results of this study showed that breast preserving surgery less negatively affects patients' quality of life than the mastectomy surgeries.

\section{Study 4}

Sertoz et al. [17] investigated the effect of breast cancer surgery type on some aspects of quality of life including body image, sexual life, self-esteem and marital adjustment. In this controlled study, 75 patients from them 50 patients had been treated by total mastectomy and the rest by total mastectomy with breast reconstruction and 50 healthy control women were investigated. All participants completed four questionnaires including self-esteem, body image, sexual satisfaction and marital adjustment. The results of this study showed that the mean scores of self-esteem and body image have a statically difference among the three groups. In the other words, the results approved that mastectomy imposes negative effects on the self-esteem and body image.

\section{Conclusion}

Breast cancer is the most common cancer among women and is one of the leading causes of women mortality in the world [13]. Despite the greet progress in early diagnosis and treatment of disease, this condition as well as its treatment options reduce the various aspects of quality of survivors' life [6-16]. Surgical treatments have the greatest negative impact on the quality of life of breast cancer patients. Although all types of breast surgery can have negative psychosocial consequences, studies have shown that breast preserving surgery has fewer negative effects than other surgery types. However, developing the more responsible social support mechanisms to maintain the life quality of surgically treated breast cancer patients should be considered as a policy option [18-20].

\section{References}

1. Prates ACL, Freitas-Junior R, Prates MFO, Veloso MdF, Barros NdM (2017) Influence of body image in women undergoing treatment for breast cancer. Rev Bras Ginecol Obstet 39(4): 175-183.
2. Silva SM, Crespo C, Canavarro MC (2012) Pathways for psychological adjustment in breast cancer: A longitudinal study on coping strategies and posttraumatic growth. Psychology \& Health 27(11): 1323-1341.

3. Gupta B, Yaduvanshi R, Trivedi JK, Nischal A (2012) A Comparative study of body image and coping style in breast cancer patients. Delhi Psychiatry Journal 15(1): 177-182.

4. Sebastián J, Manos D, Bueno M, Mateos N (2008) Body image and selfesteem in women with breast cancer participating in a psychosocial intervention program. Psychology in Spain 12(1): 13-25.

5. Fazel A, Tirgari B, Mokhber N, Koushyar MM, Esmaili H (2008) The study of mastectomy effect on the distress and quality of life in women with breast cancer. The Journal of Shahid Sadoughi University of Medical Sciences 16(3): 28-36.

6. Fingeret MC, Teo I, Epner DE (2014) Managing body image difficulties of adult cancer patients. Cancer 120 (5): 633-641.

7. Koçan S, Gürsoy A (2016) Body image of women with breast cancer after mastectomy: A Qualitative research. J Breast Health 12(4): 145-150.

8. Gomes NS, Silva SR (2013) Evaluation of the self-esteem of women who had undergone breast cancer surgery. Text Context Nursing, Florianópolis 22(2): 509-516.

9. Talebi E, Movahedi AR, Amouheidari AR, Talebi E (2015) Effects of selected aerobic activities on body self-concept of women with breast cancer undergoing radiotherapy post mastectomy. Motion behavior 22: 163-176.

10. Moreira H, Canavarro MC (2010) A longitudinal study about the body image and psychosocial adjustment of breast cancer patients during the course of the disease. Eur J Oncol Nurs 14(4): 263-270.

11. Brandão T, Schulz MS, Matos PM (2017) Psychological adjustment after breast cancer: a systematic review of longitudinal studies. PsychoOncology 26(7): 917-926.

12. Przezdziecki A, Sherman KA, Baillie A, Taylor A, Foley E, et al. (2012) My changed body: breast cancer, body image, distress and self-compassion. Psycho-Oncology.

13. Mącik D, Ziółkowska P, Kowalska M (2012) Self-perception of women after mastectomy as an ego defense mechanism. Comparison with a group of healthy women. Wspolczesna Onkol 16 (2): 184-190.

14. Akça M, Ata A, Nayır E, Erdoğdu S, Arıcan A (2014) Impact of surgery type on quality of life in breast cancer patients. J Breast Health 10(4): 222-228.

15. Zanapalıoğlu Y, Atahan K, Gür S, Çökmez A, Tarcan E (2009) Effect of breast conserving surgery in quality of life in breast cancer patients. The Journal of Breast Health 5(3): 152-156.

16. Markopoulos C, Tsaroucha A, Kouskos E, Mantas D, Antonopoulou Z, et al. (2009) Impact of breast cancer surgery on the self-esteem and sexual life of female patients. J Int Med Res 37(1): 182-188.

17. Onen SO, Elbi Mete H, Noyan A, Alper M, Kapkaç M (2004) Effects of surgery type on body image, sexuality, self-esteem, and marital adjustment in breast cancer: a controlled study. Turk Psikiyatri Derg 15(4): 264-275.

18. Chaman AK, Bahrami MA, Moosazadeh M, Bahrami E (2017) Quality of life in women with endometriosis: a systematic review and metaanalysis. World Cancer Research Journal 4(1): e839.

19. Chaman AK, Bahrami MA, Bahrami E (2017) Endometriosis psychological aspects: a literature review. J Endometr Pelvic Pain Disord 9(2): 105111.

20. Bahrami MA, Chaman AK, Bahrami E (2017) Impact of endometriosis on work productivity and activity impairment: a descriptive literature review. Bali Med J 6(20): 263-267. 
Creative Commons Attribution 4.0 International License

For possible submissions Click Here

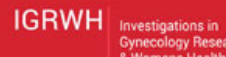 \& Womens Heanth \\ Investigations in Gynecology Research \& Womens Health}

\section{Benefits of Publishing with us}

- High-level peer review and editorial services

- Freely accessible online immediately upon publication

- Authors retain the copyright to their work

- Licensing it under a Creative Commons license

- Visibility through different online platforms 